\title{
Design and Experiments of a HAN-Based Monopropellant Thruster Using Arc-Discharge Assisted Combustion
}

\author{
By Akira KaKami, Natsuki Yamamoto, Keisuke Ideta and Takeshi TaCHIBAnA \\ Department of Mechanical Engineering, Kyushu Institute of Technology, Kitakyushu, Japan
}

(Received June 20th, 2011)

\begin{abstract}
This paper discusses a 1-N class space propulsion thruster using SHP163 monopropellant and arc discharge assisted combustion. SHP163 is a hydroxyl-ammonium nitrate (HAN)-based monopropellant, which has relatively low toxicity and reactivity to materials such as metal and polymers, and can be stored in a liquid form due to its relatively low freezing point. Arc discharge, supporting a SHP163 exothermic chemical reaction, is used as an alternative to conventional particulate catalysts. Part of the pressurant is used as working fluid for the arcjet. Tests using prototyped thrusters show that combustion started and was successfully sustained with the assistance of a 1-kW class arc discharge. Thrust chamber pressure measurements yielded a characteristic exhaust velocity efficiency of $90 \%$ at a specific power of $2.8 \mathrm{MJ} / \mathrm{kg}$.
\end{abstract}

Key Words: Chemical Propulsion Device, Plasma Assisted Combustion, Hydroxyl Ammonium Nitrate, SHP163

\section{Introduction}

Hydrazine monopropellant thrusters have been applied to the attitude control systems of both satellites and launch vehicles. Hydrazine, a colorless transparent liquid having the molecular equation $\mathrm{N}_{2} \mathrm{H}_{4}$, is readily decomposed into ammonium, hydrogen, and nitrogen through exothermic reactions when it is injected into a specific catalyst ${ }^{1)}$. Iridium-based particulate catalysts such as S405 have been used to support its chemical reaction. Because hydrazine exothermic reaction starts immediately after contacting the catalysts, hydrazine monopropellant thrusters have an advantage in quick response, which makes them suitable for attitude control.

On the other hand, hydrazine has strong toxicity and reactivity with some materials; consequently gas treatment systems are necessary for thruster ground tests. Hence, low-toxicity propellants called "green propellants" have recently been developed as alternatives to hydrazine ${ }^{2-7)}$.

Besides, iridium-based catalysts for promoting hydrazine decomposition are produced by only a few foreign makers, with resultant vulnerability regarding procurement. From this viewpoint, more available materials should be used in the thrusters. Moreover, higher specific impulse propellants generally produce augmented adiabatic flame temperatures. Increasing flame temperatures possibly deteriorates or cracks the particulate catalysts. Hence, another combustion-supporting method is necessary for applying higher performance propellants to thrusters.

In this study, we propose to apply arc plasma-assisted combustion and a newly-developed propellant SHP163 to a monopropellant thruster. Prototype thrusters were tested to show that the arc discharge stably sustains SHP163 combustion, and to evaluate characteristic exhaust velocity efficiency ( $C^{*}$-efficiency).

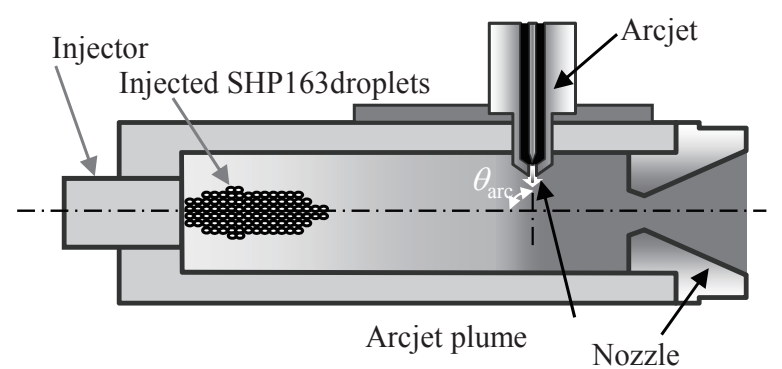

(a) Thruster with an side arcjet

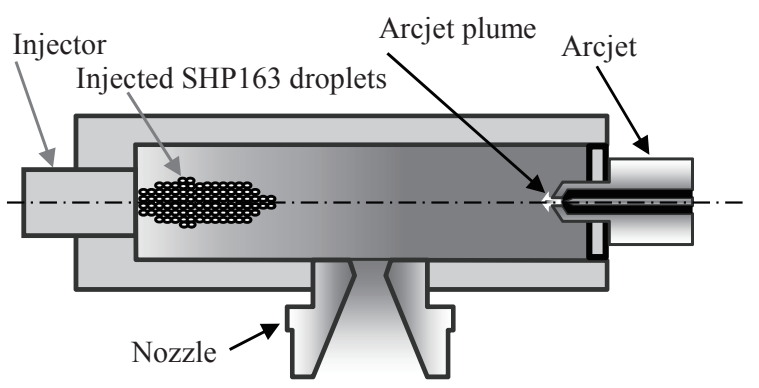

(b) Thruster with an opposing arcjet

Fig. 1. Schematic diagrams of designed thruster.

\section{Designed Thruster}

Figure 1 is a schematic diagram of the designed thrusters. An injector atomizes SHP163 and supplies its droplets into a thrust chamber, and simultaneously an arcjet supplies an arc plasma to the injected propellant. The high-temperature arc plasma, including radicals, enhances evaporation and chemical reaction of SHP163 droplets. This thruster configuration allows combustion to be sustained without conventional catalysts. 
Table 1. Characteristics of hydrazine and SHP 163.

\begin{tabular}{l|c|c}
\hline & Hydrazine & SHP163 \\
\hline Specific impulse, $\mathrm{s}$ & 211 & 254 \\
Specific impulse density, $\mathrm{s} \mathrm{kg} / \mathrm{m}^{3}$ & 211 & 346 \\
Freezing point & 1.4 & -68.0 \\
Specific weight & 1.0 & 1.4 \\
Toxicity & Strong & Weak \\
Reactivity to materials & Strong & Weak \\
\hline
\end{tabular}

The proposed thrusters use a pressurant as the working fluid of the arcjet. In general, for satellite thrusters, gases such as helium and nitrogen assist liquid-propellant feeding using their pressures. In the designed thrusters, some of the pressurant gas is used for the arcjet working fluid. This design simplifies the storage and feeding systems of the propellant and pressurant.

The designed thrusters can be categorized as chemical propulsion devices, although they use an arcjet. The arcjet just produces high-temperature flow containing radicals, and yields lower enthalpy than a chemical reaction of SHP163. Then, most of the thrust is provided by the chemical energy contained by the propellant.

SHP163 comprises HAN, methanol $\left(\mathrm{CH}_{3} \mathrm{OH}\right)$, ammonium nitrate $(\mathrm{AN})$, and water $\left(\mathrm{H}_{2} \mathrm{O}\right)$ with a weight mixture ratio of $\mathrm{HAN} / \mathrm{AN} / \mathrm{H}_{2} \mathrm{O} / \mathrm{CH}_{3} \mathrm{OH}=95 / 5 / 8 / 21$. $\mathrm{HAN}$ is a solid oxidizer that readily dissolves in water and produces high-temperature flames having relatively low molecular weights, which enhance specific impulse. Besides, it has less toxicity and reactivity to materials used for storing and supplying propellants, compared to hydrazine. Due to these preferred properties, HAN is a potential green liquid propellant and an alternative to hydrazine. On the other hand, thrust chamber pressure is expanded in the vicinity of $8 \mathrm{~atm}$ because burning rate is increased discontinuously at a back pressure of $8 \mathrm{~atm}$. In contrast, the mixture ratio of SHP163 suppresses the discontinuous expansion of the burning rate at $8 \mathrm{~atm}$. Table 1 shows a comparison of SHP163 and hydrazine. SHP163, having the advantages of specific impulse and density, reduces propellant mass and tank volume. Lower melting point eliminates the necessity for complex temperature management Weak reactivity allows the thruster to be made from readilyobtainable materials such as stainless steels.

From these points of view, the combination of SHP163 and arc discharge-assisted combustion yields various preferred characteristics for space propulsion devices such as enhanced specific impulse and improved reliability.

\section{Experimental Apparatuses}

\subsection{Designed thruster}

Figures 1 (a) and (b) and Table 2 show schematics of the designed 1-N class thruster and its configuration. Target thrust and thrust chamber pressure are $1 \mathrm{~N}$ and $0.4 \mathrm{MPa}$, respectively. The target thrust chamber pressure was selected because arc discharge is difficult to sustain at enhanced back pressures. A throat diameter of $1.7 \mathrm{~mm}$ was determined from these target values and theoretical specific impulse. All the experiments were conducted at the atmospheric pressure; hence, the nozzle
Table 2. Designed thruster configuration.

\begin{tabular}{lc}
\hline \hline Target thrust (in vacuum), N & 1.0 \\
Target thrust chamber pressure, MPa & 0.4 \\
Throat diameter, mm & 1.7 \\
Nozzle area ratio & 1.28 \\
Thrust chamber length, mm & 120 \\
Discharge current, A & $15-20$ \\
\hline
\end{tabular}

Table 3. Mass flow rates in experiment.

\begin{tabular}{c|c|c|c}
\hline \multirow{2}{*}{ NF } & \multicolumn{3}{|c}{ Mass flow rate, g/s } \\
\cline { 2 - 4 } & SHP163 & \multicolumn{2}{|c}{ Nitrogen } \\
\cline { 2 - 4 } & & Injector & Arcjet \\
\hline$\# 1$ & 0.5 & 0.1 & 0.1 \\
$\# 2$ & 0.5 & 0.16 & 0.1 \\
$\# 3$ & 0.5 & 0.1 & 0.16 \\
\hline
\end{tabular}

expansion ratio is relatively low in compared to a conventional space propulsion device.

Two types of thruster were prototyped in the current study. In the side arcjet type, discharge plasma is injected into the thrust chamber from its side, as shown in Fig. 1(a). In an opposing arcjet type, the arcjet was mounted so that the direction of the arc plasma jet opposes that of the injected SHP163 droplets, as shown in Fig.1 (b).

A coaxial-type injector was used for the prototypes because the liquid propellant fed starts to atomize beneath the injector outlet unlike impingement-type injectors, with which a fan-shaped liquid film is sometimes formed for comparatively viscous propellants. Besides, the droplet mean diameter using coaxial-type injectors is smaller than when using impingement-type injectors. Due to these properties, $\mathrm{C}^{*}$ efficiency in the case of coaxial-type injectors is greater than that of impingement-type injectors.

In this research, nitrogen was used as the working fluid of the arcjet as well as for the coaxial injector.

\subsection{Propellant supply, power source, and measurement}

Nitrogen, stored in a pressurized vessel, was supplied to both the coaxial injector and the arcjet through mass flow controllers after the nitrogen pressure was kept at $4 \mathrm{~atm}$ by a pressure regulator.

SHP163 stored in a nitrogen-pressurized tank was fed to an electromagnetic proportional valve (Fujikin, SR-100), and its mass flow rate was measured with a Coriolis mass flow meter (Oval CR003). During the tests, the opening rate of the electromagnetic valve was adjusted manually in accordance with the measured mass flow rate to keep constant SHP163 mass flow rate

A RTAI/Linux-installed desktop computer with an analog interface board (Interface, PCI-3521) captured time variations of discharge voltage, current, thrust chamber pressure, and mass flow rates of nitrogen and SHP163 and simultaneously adjusted the control voltages of the nitrogen mass flow controllers and the electromagnetic proportional valve.

A constant-current power supply with a rated voltage and current of $120 \mathrm{~V}$ and $35 \mathrm{~A}$, respectively, was used to supply a discharge current for the arcjet. At ignition, a train of $10-\mathrm{kV}$ class voltage pulses was fed by the power supply. 


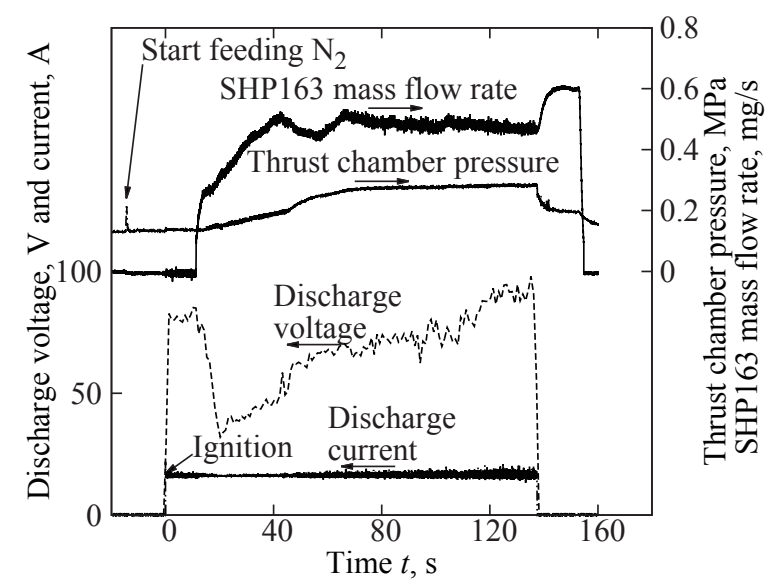

Fig. 2. Time history of discharge current, voltage thrust chamber pressure and SHP163 mass flow rate for the side arcjet type in the case with NF\#1.

Table 3 displays mass flow rates for SHP163 and nitrogen. SHP163 flow rate was $0.5 \mathrm{~g} / \mathrm{s}$ in the current study. Under $\mathrm{NF} 2$ 2, the nitrogen mass flow rate for the injector was increased to $0.16 \mathrm{~g} / \mathrm{s}$ to estimate the influence of the injector flow rate on $\mathrm{C}^{*}$ efficiency. Increasing the nitrogen flow rate reduces droplet diameters, because coaxial-type injectors atomize liquid propellant by a sharing force originating from the velocity discrepancy of liquid and gas flows. Accordingly, the injector flow rate may allow the combustion to be completed in the thrust chamber. To clarify the affects of the injector flow rate, the arcjet flow rate under NF\#3 was set at $0.16 \mathrm{~g} / \mathrm{s}$ while the total mass flow rate for $\mathrm{NF} \# 3$ was the same as that for NF\#2.

\section{Experimental Results}

\subsection{Time history}

Figure 2 illustrates the time history of discharge current, voltage, thrust chamber pressure, and SHP163 mass flow rate for the side-arcjet type thruster $120 \mathrm{~mm}$ in thrust chamber length. Time origin $t=0 \mathrm{~s}$ is the moment when the arc discharge is initiated. At $t=-19 \mathrm{~s}$, the mass flow controllers start to supply nitrogen to the coaxial injector and the arcjet, hence, thrust chamber pressure increases slightly. At $t=0 \mathrm{~s}$, arc plasma enhances thrust chamber pressure again. This increment is ascribed to arcjet enthalpy because no SHP163 is being fed to the thruster at this time.

SHP163 feeding starts at $t=7 \mathrm{~s}$. For safety, the mass flow rate of SHP163 was gradually increased for $30 \mathrm{~s}$. According to the increment of SHP flow rate, thrust chamber pressure gradually increased, and finally reached $0.3 \mathrm{MPa}$. By keeping a constant SHP163 flow rate, the thruster yields a stable thrust chamber pressure. At $t=137 \mathrm{~s}$, when the discharge current is interrupted, the thrust chamber pressure starts rapid attenuation, and this shows that the chemical reaction is interrupted soon after interrupting the discharge current.

These results show that the chemical reaction is maintained by an arc discharge. Thrusts for the designed thruster are mainly produced through chemical reactions in comparison to electric power. This is because the rise of thrust chamber pressure following arc discharge ignition is much lower than

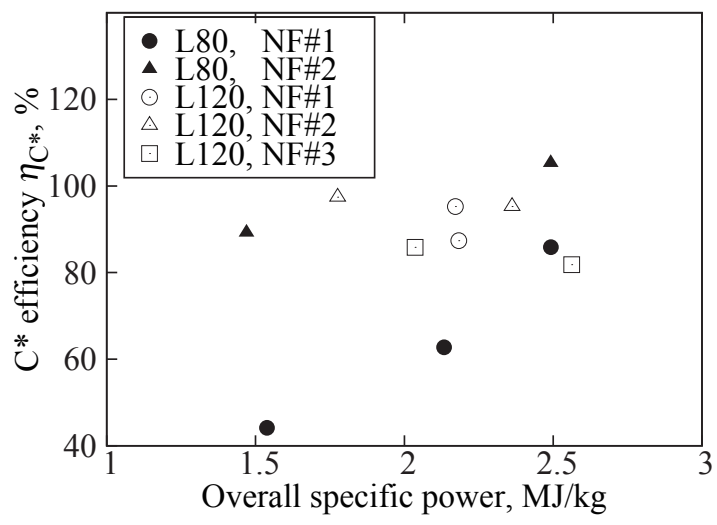

Fig. 3. Dependence of $\mathrm{C}^{*}$ efficiency $\eta \mathrm{c}^{*}$ on specific power for designed thrusters with side arcjet type thruster. L80 and L120 stand for thrust chamber lengths of 80 and $120 \mathrm{~mm}$, respectively. NF means "nitrogen mass flow rate", shown in table 3.

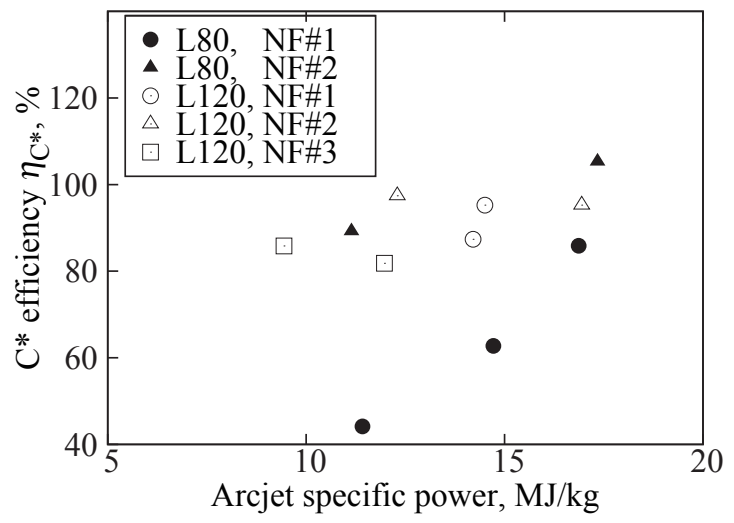

Fig. 4. Dependence of $\mathrm{C}^{*}$ efficiency $\eta \mathrm{c}^{*}$ on specific power of arcjet for designed thrusters with thrust chamber length of $120 \mathrm{~mm}$. NF means "nitrogen mass flow rate", shown in table 3.

that when combustion is sustained.

Under the other experimental conditions in the current study, the thruster yielded similar time histories.

\section{2. $C *$ efficiency of side arcjet-type thruster}

Figure 3 depicts the dependence of $C^{*}$ efficiency on overall specific power, which is the ratio of arcjet-consumed power to the sum of mass flow rate for SHP163 and nitrogen fed to the injector and arcjet. Focusing on the side arcjet type $80 \mathrm{~mm}$ in thrust chamber length, $\mathrm{C}^{*}$ efficiency increased from 44 to $85 \%$ with overall specific power under NF\#1 flow rate condition. The 120-mm long thrust chamber yielded higher $\mathrm{C}^{*}$ efficiencies ranging 85 to $97 \%$ than those with $80 \mathrm{~mm}$ long thrust chamber. This is because SHP163 droplets remain in the thrust chamber for longer period in the case of a $120-\mathrm{mm}$ thrust chamber.

Nitrogen mass flow rate to the injector influences $\mathrm{C}^{*}$ efficiency. For the $80-\mathrm{mm}$ length thrust chamber, $\mathrm{C}^{*}$ efficiency ranged from 44 to $85 \%$ under condition NF\#1, whereas it varied from 95 to $105 \%$ under condition NF\#2. This is ascribed to the dependence of gas velocity on droplet diameter of coaxial-type injectors. Sauter mean diameter (SMD) is theoretically inversely proportional to the velocity 


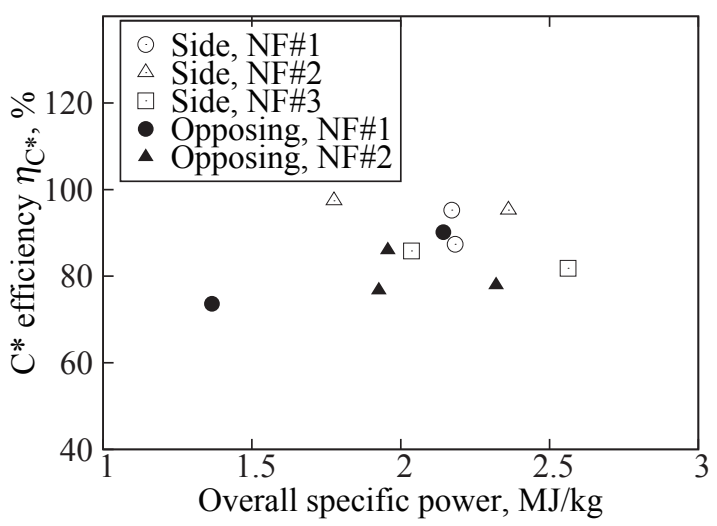

Fig. 5. Dependence of $\mathrm{C}^{*}$ efficiency $\eta \mathrm{c}^{*}$ on specific power for designed thrusters with thrust chamber length of $120 \mathrm{~mm}$. "Side" and "Opposing" shows the thrusters with side arcjet and opposing one. NF means nitrogen mass flow rate", shown in table 3.

discrepancy between gas and liquid ${ }^{10)}$. With regard to the combustion time of liquid droplets and evaporation process, a time-dominant one, generally requires a time proportional to the square of droplet diameter ${ }^{11)}$. Hence, the increment of nitrogen mass flow rate for the injector, which reduces SMD by accelerating nitrogen velocity, promotes combustion and yields a higher $\mathrm{C}^{*}$ efficiency.

In contrast, the 120 -mm thrust chamber shows a slight discrepancy in $\mathrm{C}^{*}$ efficiency between NF\#1 and \#2, although SMDs should be different for each nitrogen mass flow rate. This could be because the 120 -mm thrust chamber length is sufficiently long to complete combustion for both SMD.

The thruster under NF\#3 yields a lower $C^{*}$ efficiency than under NF\#1, 2. This could be ascribed to attenuation in arcjet specific power, which shows the power consumption per unit arcjet nitrogen mass flow rate. Figure 4 illustrates the dependence of $C^{*}$ efficiency on arcjet specific power. NF\#3 yields lower arcjet specific power than the other nitrogen mass flow rates. Hence, the arc plasma assistance of the SHP163 reaction under NF\#3 is weakened compared to those under other mass flow rate conditions. This reduced the $C^{*}$ efficiency of NF\#3.

\section{3. $C^{*}$ efficiency of opposing arcjet type thruster}

Figure 5 shows the dependence of $C^{*}$ efficiency on overall specific power for the side arcjet type and opposing arcjet type. The opposing arcjet type exhibits $C^{*}$ efficiencies ranging from 78 to $95 \%$. At almost an identical overall specific power, the side arcjet type yielded higher values than the opposing arcjet.

Nevertheless, the side arcjet thruster exhibits a higher $C^{*}$ efficiency than the true value. As shown in Fig. 3, that efficiency exceeded $100 \%$ under certain conditions. When calculating $C^{*}$ efficiency, theoretical $C^{*}$ values are evaluated, taking arc discharge power into consideration. Hence, $C^{*}$ efficiency would never exceed $100 \%$. From this exceeding values, $C^{*}$ efficiency is overestimated for side arcjet type.

This is partially because the thrust chamber wall is directly heated by the arcjet. With the side arcjet, plume impinged onto the thrust chamber wall. As a result, it has a locally heated area. Moreover, because the arcjet had been heating the thrust chamber wall before liquid propellant injection, the thrust chamber wall accumulated plume-originating heat, which then assisted the SHP163 reaction after initiating combustion. Hence, $C^{*}$ efficiency would be lower than the values evaluated here if the thruster achieves thermal equilibrium with a sufficiently long thruster operation.

On the other hand, the opposing arcjet type thruster yields more accurate $\mathrm{C}^{*}$ efficiencies because this thruster cannot accumulate heat locally.

\section{Summary}

The following is a summary of the current paper.

1. To enhance environmental compatibility, storability of propellant, and availability of propellant ingredients and thruster materials material, we proposed applying SHP163, a HAN based monopropellant, and arc discharge assisted combustion to a small space propulsion device.

2. Two types of thruster were prototyped: side arcjet type, with injecting the arc plasma from the side of the thrust chamber, and opposing arcjet type, with opposing injector and the arcjet.

3. Tests using the prototypes showed that the designed thruster successfully yielded thrust chamber pressure without fluctuations, i.e., stable combustion.

4. Increasing the nitrogen mass flow rate for the injector develops $\mathrm{C}^{*}$ efficiencies. This is ascribed to the reduction of Sauter Mean Diameter of SHP163 liquid propellant.

5. The side-type arcjet exhibited $C^{*}$ efficiencies varying from 44 to $105 \%$.

6. Under some experimental conditions, the side-arcjet type thruster $C^{*}$ efficiency was overestimated because it exceeded $100 \%$, whereas the theoretical characteristic exhaust velocity was evaluated with consideration given to arc jet enthalpy.

7. The opposing arcjet type thruster yields $C^{*}$ efficiencies ranging from 73 to $90 \%$.

\section{Acknowledgments}

This work was partially supported by KAKENHI, Grants-in-Aid for Scientific Research (A) (21246129).

\section{References}

1) Sutton, G.P. and Biblarz, O.: Rocket Propulsion Elements 7th edition. JOHN WILEY \& SONS, INC., New York, 2001.

2) Kakami, A., Yokote, J., Ebara I., Shuzenji, K. and Tachibana, T.: Design and Experiment of Thrusters using Dimethyl Ether, Journal of the Japan Society for Aeronautical and Space Sciences, 57(2009), pp. 190-195 (in Japanese).

3) Katsumi, T. et. al.: COMBUSTION CHARACTERISTICS OF HAN-BASED LIQUID MONOPROPELLANT, International Journal of Energetic Materials and Chemical Propulsion, 2(2008), pp.123-137, 2008.

4) Junichiro, A., et. al.: Consideration of Atmospheric Pressure Plasma for the Green-Propellant Reaction, Plasma Application and Hybrid Functionally Materials, 19 February (2010), pp. $27-28$ 
5) Jankovsky, R.S.: HAN-Based Monopropellant Assessment for Spacecraft, 32nd AIAA/ASME/SAE/ASEE Joint Propulsion Conference, Lake Buena Vista, Florida, AIAA 96-2863, 1996.

6) Hisatsune, K. et. Al.: Development of HAN-Based Liquid Propellant Thruster, Proceedings of Asian Joint Conference on Propulsion and Power, 2005.

7) Nagase, S., Miyazaki, S., Ayabe, M. and Kohno, M.: "A Preliminary work on HAN/HM-Based Monopropellant," Proceedings of 24th International Symposium on Space Technology and Science, Miyazaki, Japan, ISTS 2004-a-26, 2004.
8) NASA Glenn Research Center, Chemical Equilibrium with Applications (CEA), available at http://www.grc.nasa.gov/WWW/CEAWeb/.

9) Vigor Yang, et al.: Liquid Rocket Thrust Chambers: Aspects of Modeling, Analysis, and Design, Progress in Astronautics and Aeronautics, Volume 200, American Institute of Aeronautics and Astronautics, 2004.

10) Forman A. Williams: “Combustion Theory," Perseus Books Publishing L.L.C., 1985. 